\title{
Paleomagnetic investigation of rhyolite lava: Is rhyolite with clearly marked flow structure a high-fidelity geomagnetic field recorder?
}

\author{
Koji Uno ${ }^{1}$, Yoko Kaneshige ${ }^{2}$, Kuniyuki Furukawa ${ }^{3}$, Taro Shinmura ${ }^{4}$, and Masaya Miyoshi ${ }^{5}$ \\ ${ }^{1}$ Graduate School of Education, Okayama University, 3-1-1 Tsushimanaka, Kita-ku, Okayama 700-8530, Japan \\ ${ }^{2}$ Faculty of Education, Okayama University, 3-1-1 Tsushimanaka, Kita-ku, Okayama 700-8530, Japan \\ ${ }^{3}$ Faculty of Business Administration, Aichi University, 4-60-6 Hiraike-cho, Nakamura-ku, Nagoya 453-8777, Japan \\ ${ }^{4}$ Faculty of Economics, Kumamoto Gakuen University, 2-5-1 Oe, Kumamoto 862-8680, Japan \\ ${ }^{5}$ Faculty of Education and Regional Studies, University of Fukui, 3-9-1 Bunkyo, Fukui 910-8507, Japan
}

(Received June 27, 2012; Revised August 27, 2012; Accepted August 29, 2012; Online published May 7, 2013)

\begin{abstract}
Rhyolite is a common volcanic rock; however, few studies have focused on the remanent magnetization of rhyolite lava, and few paleomagnetic studies have successfully investigated rhyolite lavas. We suspect that problems associated with paleomagnetic studies of rhyolite may be due to the nearly ubiquitous flow structure in rhyolite lava. In this study, we examined a thick rhyolite lava flow with clearly marked flow structure to assess its ability to record a consistent paleomagnetic direction, using material penetrated by two drill cores. Progressive thermal demagnetization isolated two magnetization components. A high-temperature component from each of the two cores yields inclinations that differ from each other. The low-temperature component had those that agreed with each other, and were also consistent with the direction expected from a geocentric axial dipole field. The modification of direction of the high-temperature component may be explained by post-magnetization acquisition tilting. The development of flow structure also leads to distortion of directions of the component, which is observed at stratigraphic positions where the volume fraction of light-colored parts of the flow structure $>30 \%$. In the case of silicic lava, the low-temperature component may retain directions parallel to the ambient field direction at the time of lava emplacement.
\end{abstract}

Key words: Drill cores, flow structure, remanent magnetization, rhyolite lava.

\section{Introduction}

Volcanic rocks have long been recognized as good recorders of the geomagnetic field corresponding to the time of their formation. Because volcanic rocks are free from the effect of inclination shallowing that could be introduced from the compaction of sediments during syn- or post-depositional processes, volcanic rocks are considered to provide higher fidelity paleofield records than sedimentary rocks. In some recent studies, paleomagnetic directions derived from volcanic rocks were used to check the validity of coeval directions inferred from sedimentary rocks (e.g., Gilder et al., 2003; Hankard et al., 2007; Tan et al., 2010).

Rhyolite lava is a common volcanic rock in continental regions and can also be considered to be a useful source of paleomagnetic data. However, only few studies have focused on paleosecular variation, magnetostratigraphy or plate reconstruction analysis using the remanent magnetization of rhyolite lavas. A database of paleomagnetic poles for the East Asian continent since the Late Permian, for example, includes only two poles derived from rhyolite lavas (Enkin et al., 1992).

The reliability of remanent magnetization directions from rhyolite lavas would appear problematic, because few

Copyright (c) The Society of Geomagnetism and Earth, Planetary and Space Sciences (SGEPSS); The Seismological Society of Japan; The Volcanological Society of Japan; The Geodetic Society of Japan; The Japanese Society for Planetary Sciences; TERRAPUB.

doi:10.5047/eps.2012.08.013 paleomagnetic studies have successfully investigated rhyolite lavas. Singer and Brown (2002) reported Pleistocene $(0.9 \mathrm{Ma})$ directions from rhyolite lavas; one of three study sites was found to show a declination $\sim 180^{\circ}$ apart from the others, with consistent intermediate inclination of the same polarity between them. Hoshi (2002) presented Miocene (ca. $14 \mathrm{Ma}$ ) paleomagnetic data from rhyolite lavas showing large disagreement $\left(\sim 35^{\circ}\right)$ of their direction from the expected paleomagnetic direction for the same region. In contrast, Ganerød et al. (2010) reported Paleocene (ca. $61 \mathrm{Ma}$ ) magnetization directions from rhyolite lavas, which were consistent with those from determined from the overlying and underlying basalts.

Being highly viscous, rhyolite lavas often show heterogeneous texture, unlike andesitic and basaltic lavas. Flow structure, one of the characteristics of rhyolite lava, may offer a clue about the changes in the direction of remanent magnetization in rhyolite lava during the development of the structure-heterogeneous texture in rocks may cause the deflection of the remanent magnetization to a direction different from the original one. In the case of metamorphic rocks, for example, the deflection of the direction of characteristic remanent magnetization was observed to be a function of the degree of anisotropy of magnetic susceptibility (Bartolomeu Raposo et al., 2003). The disagreement between the observed paleomagnetic direction of rhyolite lava and the expected one may be a function of the development of the flow structure. 

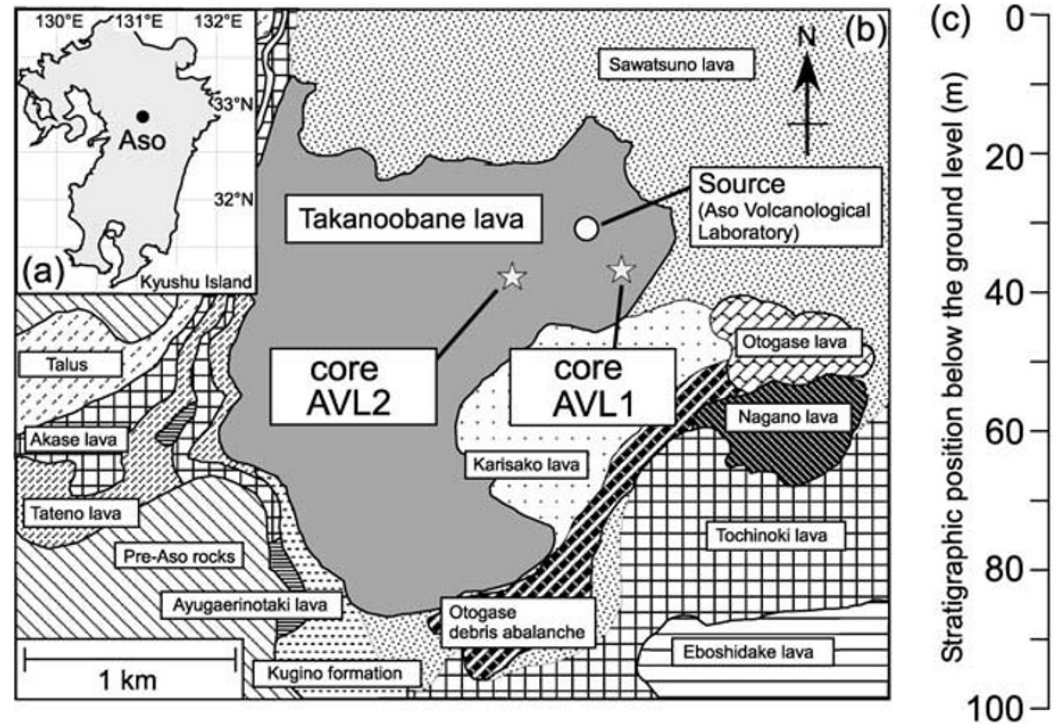

Glassy part Crystalline part
AVL1 AVL2

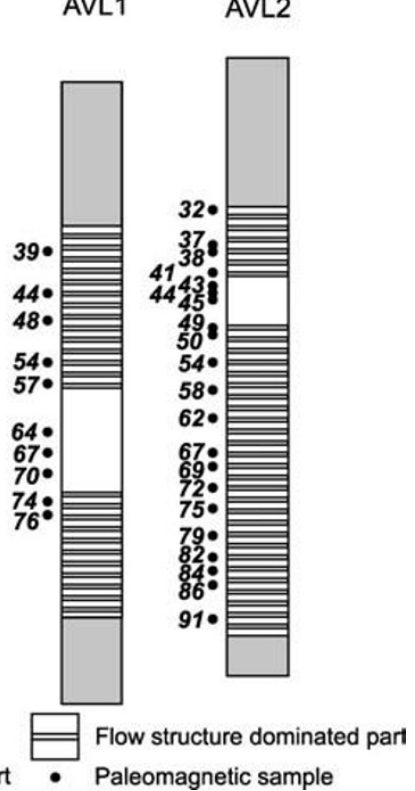

Fig. 1. (a) An outline map of Kyushu Island showing the location of Aso volcano. (b) Geologic map showing the distribution of the Takanoobane rhyolite lava and its source location, and the drilling sites (AVL1 and AVL2), after Furukawa et al. (2010). (c) Cross sections through AVL1 and AVL2 after Furukawa and Kamata (2005).

Another complication is the mechanical deformation of silicic lava during stages of cooling of lava flow after remanence acquisition; such deformation is independent of the development of the ductile texture (e.g., the flow structure). Nakada et al. (1995) observed that in many cases, the mechanical deformation of a silicic lava flow could initiate at areas proximal to the crater of lava domes, and then propagate to more distal areas; this is brought about by subsequent magma supply. This style of deformation of the lava flow may therefore cause the paleomagnetic direction of rhyolite lava to deviate from the expected one, regardless of the degree of development of the flow structure.

We conducted a paleomagnetic study of a thick rhyolite lava flow with clearly marked flow structure to evaluate if it records a consistent paleomagnetic direction, in both the vertical and horizontal perspectives. Two drill cores from the Takanoobane rhyolite lava of Aso volcano in Japan were used in this study. Because the Takanoobane rhyolite lava is completely penetrated by the drill cores, and because the two cores were drilled at different distances from the source, the cores are expected to provide an opportunity to define the vertical and horizontal variations in the direction of remanent magnetization. Generally, vertical sampling of rhyolite is limited to a certain stratigraphic interval because of its great thickness; this case study enabled us to illustrate not only localized deformation but also broader scale deformation features.

\section{Takanoobane Rhyolite Lava}

The Takanoobane rhyolite lava is located at the Aso caldera on Kyushu Island, Japan (Fig. 1(a)), and forms a dome-like structure. The lava has been $\mathrm{K}$-Ar dated at $51 \pm 5$ ka (Matsumoto et al., 1991). The source of the lava is situated on a hill near the Aso Volcanological Laboratory of Kyoto University $\left(32^{\circ} 53^{\prime} 7.77^{\prime \prime} \mathrm{N}, 131^{\circ} 0^{\prime} 23.85^{\prime \prime} \mathrm{E}\right)$ (Fig. 1(b)), and the lava flows down mostly westward to southwestward. The volume of the lava is estimated to be $0.14 \mathrm{~km}^{3}$ (Miyabuchi et al., 2004), and bulk rock chemistry of the lava is 70 to $72 \mathrm{SiO}_{2} \mathrm{wt} \%$ (Miyoshi et al., 2005, 2011). We examined two continuous drill cores of the Takanoobane rhyolite lava (cores AVL1 and AVL2) provided by the Aso Volcanological Laboratory of Kyoto University. The two drill cores completely penetrate the lava; the thickness of the lava in cores AVL1 and AVL2 are $91.4 \mathrm{~m}$ and $91.0 \mathrm{~m}$, respectively. The locations of AVL1 and AVL2 are $230 \mathrm{~m}$ and $340 \mathrm{~m}$ away horizontally from the source, respectively.

The Takanoobane rhyolite lava in the two cores is composed of an inner crystalline part, and marginal glassy parts (upper and basal glassy layers) (Furukawa and Kamata, 2005; Furukawa et al., 2010) (Fig. 1(c)). In both cores, the inner crystalline rhyolite shows a significant flow structure, characterized by light-colored bands a few millimeters to $3 \mathrm{~cm}$ thick. Furukawa and Kamata (2005) noted that the light-colored bands are made up of aggregates of deformed minute cavities 5-50 $\mu \mathrm{m}$ in diameter with a vesicularity of $40-50$ vol\%. The macroscopic shape of the minute cavity aggregates (the flow structure) in cores AVL1 and AVL2 are generally lenticular and tabular shapes, respectively. The flow structure in core AVL1 makes the angle of $10-30^{\circ}$, and $<20^{\circ}$ to the horizontal plane in the upper and lower part of the crystalline rhyolite, respectively. The structure in core AVL2 makes the angle of $30-40^{\circ}, 20-30^{\circ}$, and $<20^{\circ}$ to the horizontal plane in the upper, middle and lower part, respectively (Furukawa and Kamata, 2005).

Ten samples from core AVL1 and twenty-one samples from AVL2 of the inner crystalline rhyolite were collected, and specimens with $25 \mathrm{~mm}$ diameter and $22 \mathrm{~mm}$ length were prepared from each sample for paleomagnetic analysis (Fig. 1(c)). Because these cores had been divided into 1-m sections for storage, and therefore, not azimuthally 
AVL2-72
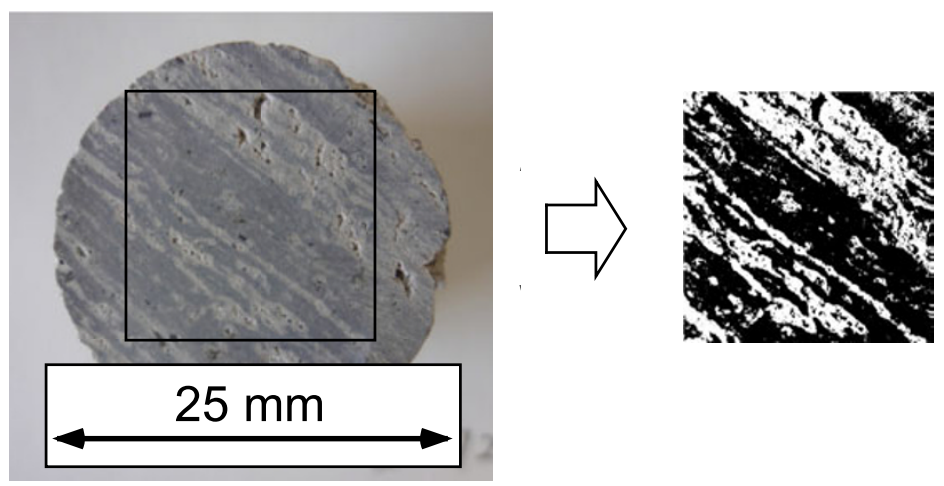

Fig. 2. Volume fraction of light-colored bands considered as a measure of the area ratio of white pixels to entire surface area.

(a)

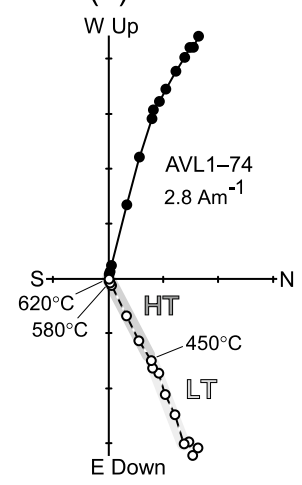

(b)

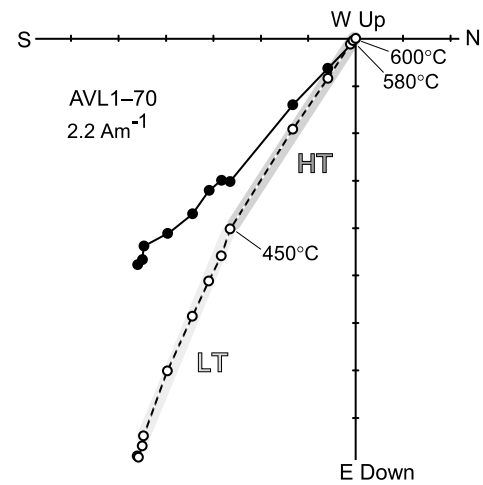

(c)

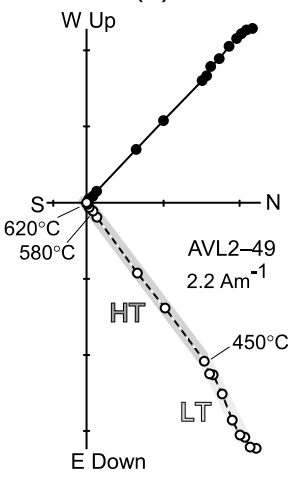

(d)

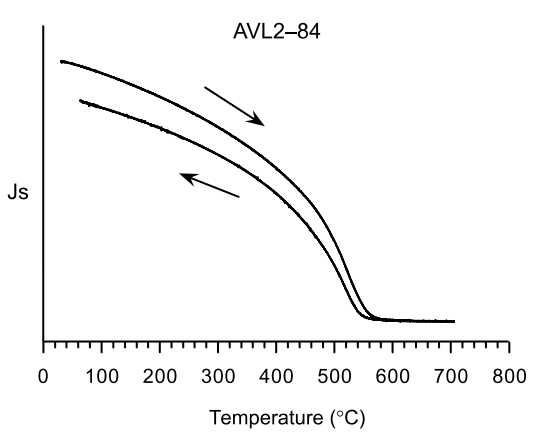

Fig. 3. (a-c) Orthogonal demagnetization diagrams of representative thermal demagnetization results of the Takanoobane rhyolite lava showing the high-temperature (HT) and low-temperature (LT) components. Solid and open symbols represent projection on horizontal and vertical planes, respectively. (d) Thermomagnetic analysis in air.

oriented, we arbitrarily defined the azimuth of $0^{\circ}$ (i.e., the north) based on the dip direction of the flow structure for each sample. In addition, the degree of development of the flow structure for each specimen was measured according to the following method. Using digital-editing software, we simplified a photo image of the polished surface of a specimen to a black-and-white image, after which an area that consists of the light-colored bands was reduced to white (Fig. 2). The volume fraction of the light-colored bands was defined as the area ratio of white pixels, and was regarded as the degree of development of the flow structure for the specimen.

\section{Paleomagnetism}

Natural remanent magnetizations (NRMs) were measured with a Natsuhara SMM-85 spinner magnetometer at Okayama University. All specimens were subjected to progressive thermal demagnetization treatment using a Natsuhara TDS- 1 thermal demagnetizer in steps of $50^{\circ} \mathrm{C}$ in the temperature range of $100-500^{\circ} \mathrm{C}$. Demagnetization steps of 20 or $30^{\circ} \mathrm{C}$ were used in the temperature range above $500^{\circ} \mathrm{C}$. Results for each specimen were plotted on orthogonal vector diagrams (Zijderveld, 1967) to evaluate their demagnetization behaviors. Principal component analysis (Kirschvink, 1980) techniques were used to estimate the di- rections of the observed magnetic components. Thermomagnetic analysis in a magnetic field of $0.8 \mathrm{~T}$ was carried out with an Eiko Curie balance at Kyoto University. Samples were heated to $700^{\circ} \mathrm{C}$ at a constant rate of $8^{\circ} \mathrm{C}$ min-1 and cooled at the same rate in air.

Initial NRM intensity of the rhyolite ranged between $7 \times 10^{-1}$ and $3 \mathrm{~A} \mathrm{~m}^{-1}$, with most NRM intensities on the order of $1 \mathrm{~A} \mathrm{~m}^{-1}$. Thermal demagnetization revealed a low-temperature component, which was identified after the removal of unstable remanence in the first two or three steps of treatment $\left(\sim 150^{\circ} \mathrm{C}\right)$. The most commonly observed maximum unblocking temperature of this low-temperature component was $450^{\circ} \mathrm{C}$ (Fig. 3). After elimination of the low-temperature component, a high-temperature component decays toward the origin. A large fraction of the high-temperature component is demagnetized by $580^{\circ} \mathrm{C}$, and little change in direction is observed after demagnetization at temperatures above $580^{\circ} \mathrm{C}$, suggesting that the high-temperature component largely resides in magnetite, with a small contribution from hematite. The component that decays to the origin is generally unblocked at temperatures between $600^{\circ} \mathrm{C}$ and $660^{\circ} \mathrm{C}$.

The thermomagnetic results show a single Curie temperature of $560^{\circ} \mathrm{C}$ that is indicative of low-Ti titanomagnetite, and show that the presence of hematite is not demonstra- 
High-temperature component

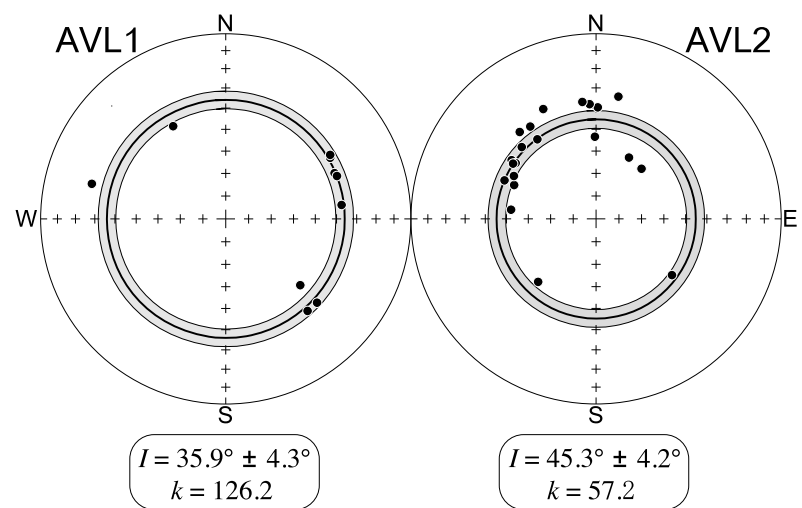

Low-temperature component

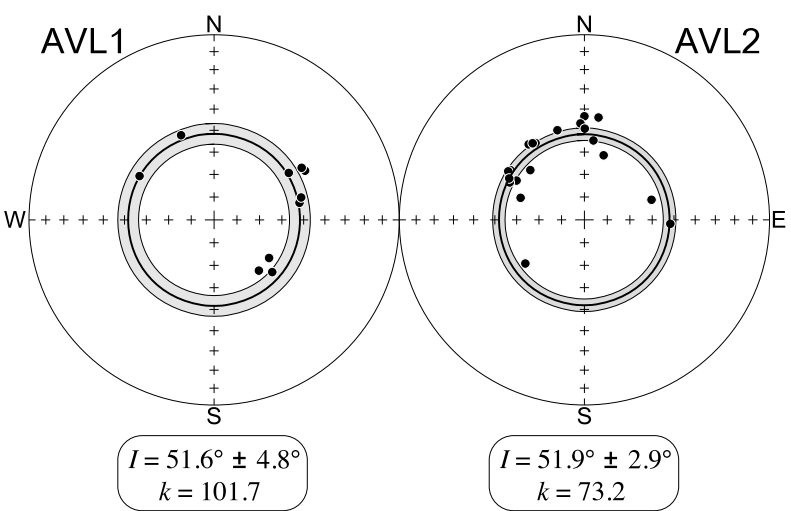

Fig. 4. Equal area projections of the directions of magnetization of the high- and low-temperature components for samples from cores AVL1 and AVL2. Solid symbols represent projection onto the lower hemisphere. Solid bold circles denote mean inclination (with associated 95\% confidence limits).

bly significant. The single Curie temperature suggests that both the low- and high-temperature components reside essentially in a single-phase titanomagnetite.

The paleomagnetic directions of the high- and lowtemperature components from cores AVL1 and AVL2 is illustrated in Fig. 4. In each projection, directions are characterized by consistent inclinations and variable declinations, which could be due to a variation in the dip direction of the flow structure at the time of emplacement of the lava. That is, the dip direction may not be consistent throughout the lava section. Accordingly, an inclination-only statistics method (McFadden and Reid, 1982) was employed to determine a mean inclination. From this, the fidelity of the acquisition of remanent magnetization direction was examined. Mean inclinations of the high-temperature component for cores AVL1 and AVL2 were found to be $35.9^{\circ} \pm 4.3^{\circ}$ and $45.3^{\circ} \pm 4.2^{\circ}$, respectively. The two inclinations are significantly different from each other at the $95 \%$ confidence level. Mean inclinations of the low-temperature component for cores AVL1 and AVL2 were found to be $51.6^{\circ} \pm 4.8^{\circ}$ and $51.9^{\circ} \pm 2.9^{\circ}$, respectively. They are indistinguishable from each other, and also indistinguishable from the direction expected from a geocentric axial dipole field at the sampling site $\left(I=52.3^{\circ}\right)$ at the $95 \%$ confidence level.

\section{Discussion}

The Takanoobane rhyolite lava yields two remanent magnetization components, both of which are considered to be of thermoremanent magnetization (TRM) origin. These components are considered primary in origin because of the following reasons. (1) A $51 \mathrm{kyr}$ exposure in the magnetic field is expected to result in a laboratory unblocking temperature of a viscous overprint below $200^{\circ} \mathrm{C}$ for magnetite (Pullaiah et al., 1975), which is less than that of the observed low-temperature component by $>250^{\circ} \mathrm{C}$. (2) Optical microscopic observations of polished thin sections of rhyolite under transmitted and reflected light indicate little or no chemical alteration after its emplacement in both magnetic minerals and other phenocrysts. (3) The thermomagnetic results show a single magnetic phase that is indicative of low-Ti titanomagnetite. These observations provide evidence for a primary origin of the observed remanences.
The high-temperature components from both cores, whose directions differ from each other, do not retain inclinations parallel to the ambient geomagnetic field direction at the time of lava emplacement. Conversely, the lowtemperature component from both cores gives records of inclinations along the ambient field direction, as shown by the coincidence of direction between both cores and the axial dipole field. For each core, the amount of inclination deviation of the high-temperature component from the low-temperature component is calculated-the mean inclination of the high-temperature components of cores AVL1 and AVL2 is $15.7^{\circ} \pm 6.4^{\circ}$ and $6.6^{\circ} \pm 5.1^{\circ}$, respectively, shallower than that of the corresponding low-temperature components.

There appears to be, in particular for core AVL1, consistently shallow inclinations in the high-temperature component throughout the section (Fig. 4), within which dip direction of the flow structure varies with depth in the flow as mentioned above. Figure 4 is drawn by orienting the dip direction of the flow structure toward $0^{\circ}$, and, therefore, it could be considered that a consistent inclination was acquired by the rhyolite at the time of lava formation, regardless of the attitude of the flow structure relative to the ambient field direction. These observations are interpreted to demonstrate that the shallow-inclination component cannot be attributed to the slope of the flow structure, and in some cases to its associated anisotropy.

The shallow-inclination component can probably be attributed to tilting associated with the development of the rhyolite dome. Endogenous growth of lava domes occurs by the subsequent supply of highly viscous magma and facilitates uplifting and tilting of dome materials (Nakada et $a l ., 1995)$. Tilting occurs to a greater degree at areas proximal to the crater than at distal ones. Therefore, tilting is expected to have taken place more significantly in core AVL1 (taken $230 \mathrm{~m}$ from the source), compared to core AVL2 (340 $\mathrm{m}$ from the source). Because cores AVL1 and AVL2 are located slightly to the south of the crater, the sites of the cores are anticipated to be tilted southward due to endogenous growth of the lava dome, which would result in shallowing of the north-directed magnetization that was already acquired. 
High-temperature component
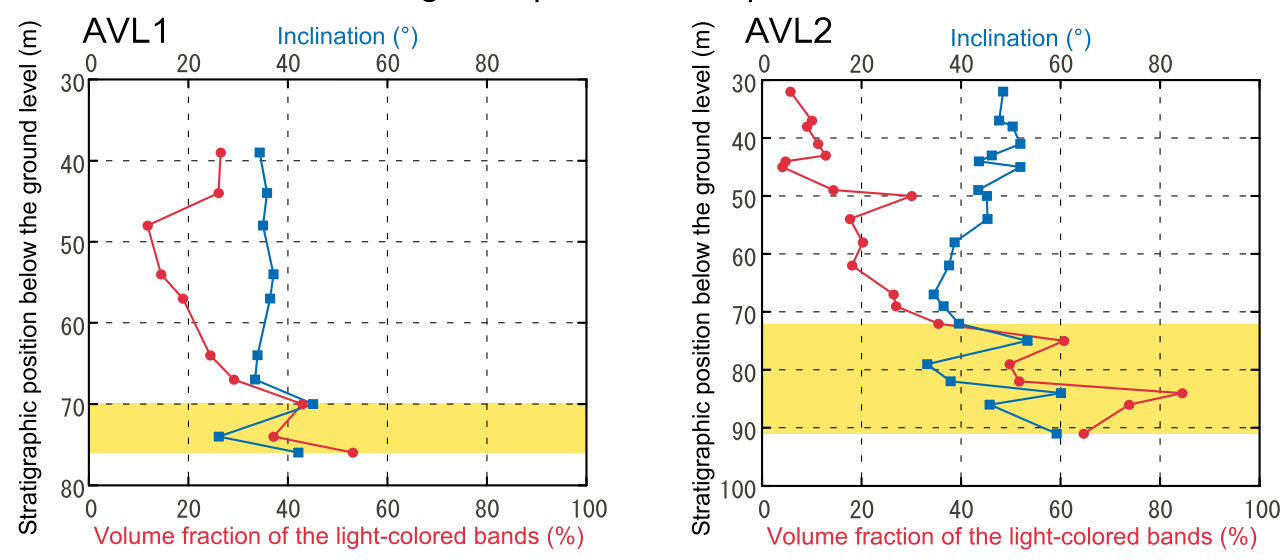

Low-temperature component
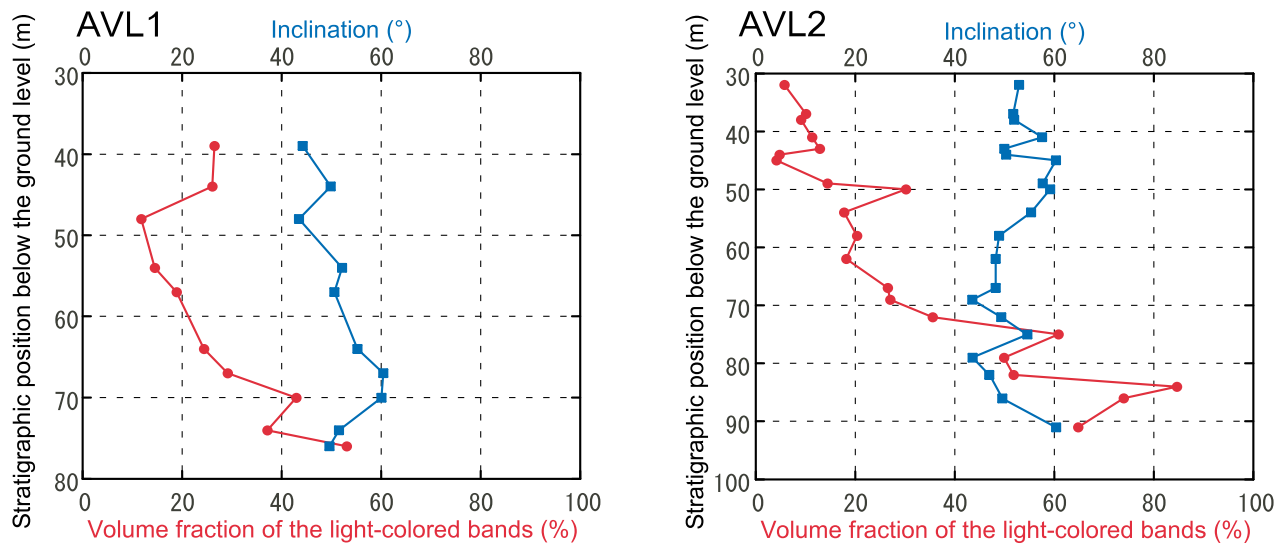

Fig. 5. Plots of inclination and volume fraction of the light-colored bands as a function of the core depth. For the high-temperature component of each core, the yellow colored area denotes the stratigraphic position with the volume fraction of the light-colored bands $>30 \%$.

There appear to be two other possible explanations for the shallow-inclination component-one is flow brecciation, and the other is localized deformation along the lava margin. (1) Breccia clasts may have been tilted toward flow margins and could have resulted in shallow inclinations. However, it would be expected that the shallow inclinations would be exclusively at the upper and basal part of silicic lava flow (Manley and Fink, 1987; Smith, 1996). In the present case however, the shallow inclinations are observed in the entire flow. (2) Core AVL1 is located at marginal area of the lava flow and may have suffered tilting due to tension that arises at the margin. However, the inclination shallowing is also observed even at the site of core AVL2 that is located on the main stream of lava flow continued down southwestward (Fig. 1). Therefore, we infer that the hightemperature component was produced by tilting of the lava dome due to endogenous growth, after the lava had been cooled to a temperature as low as $450^{\circ} \mathrm{C}$.

Detailed examination of the inclination from both cores shows a fluctuation in the high-temperature component at the basal part of the crystalline rhyolite namely, greater than $\sim 70 \mathrm{~m}$ below the ground level for each core (Fig. 5). In this part of the flow, inclination values for cores AVL1 and AVL2 fluctuate within the ranges of 26.1-45.1 ${ }^{\circ}$ and $33.2-60.1^{\circ}$, respectively, which are large when compared to those from samples above $\sim 70 \mathrm{~m}$ below the ground level, these being within the ranges of $33.4-37.1^{\circ}$ and $34.5-51.9^{\circ}$ for AVL1 and AVL2, respectively. We also observe that the basal part of the flow below $\sim 70 \mathrm{~m}$ from the ground level has a relatively high volume fraction of light-colored bands (greater than 30\%, yellow colored area in Fig. 5). This could be interpreted as being an effect of the modification of remanence direction as a result of the development of flow structure, because the light-colored bands are the fundamental products of the development of the flow structure (Furukawa et al., 2010). Because the high-temperature component displays linear characteristics during progressive thermal demagnetization (Fig. 3), the modification appears to have occurred once at around $450^{\circ} \mathrm{C}$ during the cooling. The light-colored bands show the vesicularity of $40-50 \mathrm{vol} \%$ and are composed of aggregates of significantly deformed minute cavities (Furukawa et al., 2010), suggesting that the zones where the flow structure develops could have space to accommodate deformation and compaction, likely leading to distortion of remanence directions, in response to subsequent lava intrusion.

One may note a fluctuation in the inclination of the lowtemperature component with depth in the flow from both cores (Fig. 5). However, the variation in inclination for the low-temperature component is smaller than that for the high-temperature component. The inclination of the lowtemperature component for both cores varies by $16.9^{\circ}$ from 
minimum to maximum, while that of the high-temperature component for cores AVL1 and AVL2 varies by $19.0^{\circ}$ and $26.9^{\circ}$, respectively. Therefore, we interpret this result to show that the rhyolite lava did not suffer deformation after acquisition of magnetization to an extent sufficient to lead to fluctuation in inclination of the low-temperature component.

Based on the character of the high-temperature components of magnetization in our samples, two factors are considered to be responsible for the modification of the remanence direction in the rhyolite lava-one is tilting due to the endogenous growth of a lava dome, which is a common phenomenon during silicic lava eruption, and the other is the development of the flow structure, which is marked by a higher volume fraction of the light-colored bands.

In contrast to the high-temperature component, the lowtemperature component is interpreted to retain the direction parallel to the ambient geomagnetic field direction at the time of lava emplacement. Although remanences that mirror ancient geomagnetic field direction are generally observed over a range of high laboratory unblocking temperatures during thermal demagnetization and often appear after removal of lower-temperature components, this does not appear to be the case for this rhyolite lava flow. In the case of silicic lava, it is considered that the direction of lowertemperature components may more accurately reflect that of the ambient geomagnetic field at the time of lava emplacement rather than higher-temperature components. In other words, we would identify the lower-temperature component as the remanence acquired after any deformation has been completed.

Acknowledgments. We thank Dr. Yasuaki Sudo and the staff of the Aso Volcanological Laboratory, Kyoto University for access to the drill cores of the Takanoobane rhyolite lava. We also thank Dr. Naoto Ishikawa for allowing us to use the paleomagnetic and rock magnetic laboratory. We are grateful to Dr. John Geissman, Dr. Akira Takada and the editor Dr. Toshitsugu Yamazaki for valuable suggestions for improving the manuscript.

\section{References}

Bartolomeu Raposo, M. I., M. S. D’Agrella-Filho, and R. Siqueira, The effect of magnetic anisotropy on paleomagnetic directions in high-grade metamorphic rocks from the Juiz de Fora Complex, SE Brazil, Earth Planet. Sci. Lett., 209, 131-147, 2003.

Enkin, R. J., Z. Yang, Y. Chen, and V. Courtillot, Paleomagnetic constraints on the geodynamic history of the major blocks of China from the Permian to the present, J. Geophys. Res., 97, 13953-13989, 1992.

Furukawa, K. and H. Kamata, Internal structures of the Takanoobane Rhyolite Lava in the western part of Aso caldera, Japan, J. Geol. Soc. Jpn., 111, 590-598, 2005.

Furukawa, K., K. Uno, and I. Miyagi, Mechanisms of oxidation and degassing in the Takanoobane rhyolite lava of Aso Volcano, Japan, J. Volcanol. Geotherm. Res., 198, 348-354, 2010.
Ganerød, M., M. A. Smethurst, T. H. Torsvik, T. Prestvik, S. Rousse, C. McKenna, D. J. J. van Hinsbergen, and B. W. H. Hendriks, The North Atlantic Igneous Province reconstructed and its relation to the Plume Generation Zone: The Antrim Lava Group revisited, Geophys. J. Int., 182, 183-202, 2010.

Gilder, S., Y. Chen, J.-P. Cogné, X. Tan, V. Courtillot, D. Sun, and Y. Li, Paleomagnetism of Upper Jurassic to Lower Cretaceous volcanic and sedimentary rocks from the western Tarim Basin and implications for inclination shallowing and absolute dating of the M-0 (ISEA?) chron, Earth Planet. Sci. Lett., 206, 587-600, 2003.

Hankard, F., J.-P. Cogné, X. Quidelleur, A. Bayasgalan, and P. Lkhagvadorj, Palaeomagnetism and $\mathrm{K}-\mathrm{Ar}$ dating of Cretaceous basalts from Mongolia, Geophys. J. Int., 169, 898-908, 2007.

Hoshi, H., Paleomagnetic direction of the Kumano Acidic Igneous Rocks, Kii peninsula, Japan, Bull. Geol. Surv. Jpn., 53, 43-50, 2002.

Kirschvink, J. L., The least-square line and plane and the analysis of palaeomagnetic data, Geophys. J. R. Astron. Soc., 62, 699-718, 1980.

Manley, C. R. and J. H. Fink, Internal textures of rhyolite flows as revealed by research drilling, Geology, 15, 549-552, 1987.

Matsumoto, T., K. Uto, K. Ono, and K. Watanabe, K-Ar age determinations for Aso volcanic rocks-concordance with volcanostratigraphy and application to pyroclastic flows, The Volcanological Society of Japan 1991 Fall Meeting, p. 73, 1991.

McFadden, P. L. and A. B. Reid, Analysis of palaeomagnetic inclination data, Geophys. J. R. Astron. Soc., 69, 307-319, 1982.

Miyoshi, M., T. Shibata, M. Yoshikawa, T. Sano, T. Shinmura, and T. Hasenaka, Genetic relationship between post-caldera and caldera-forming magmas from Aso volcano, SW Japan: Constraints from $\mathrm{Sr}$ isotope and trace element compositions, J. Mineral. Petrol. Sci., 106, 114-119, 2011.

Miyoshi, M., T. Hasenaka, and T. Sano, Genetic relationship of the compositionally diverse magmas from Aso post-caldera volcanism, Bull. Volcanol. Soc. Jpn., 50, 269-283, 2005.

Miyabuchi, Y., N. Masuda, and K. Watanabe, Geologic history of the western part of post-caldera central cones of Aso volcano, southwestern Japan, based on stratigraphic relationships between lava flows and airfall tephra layers, Bull. Volcanol. Soc. Jpn., 49, 267-282, 2004.

Nakada, S., Y. Miyake, H. Sato, O. Oshima, and A. Fujinawa, Endogenous growth of dacite dome at Unzen volcano (Japan), 1993-1994, Geology, 23, 157-160, 1995.

Pullaiah, G., E. Irving, K. L. Buchan, and D. J. Dunlop, Magnetization changes caused by burial and uplift, Earth Planet. Sci. Lett., 28, 133$143,1975$.

Singer, B. and L. L. Brown, The Santa Rosa Event: ${ }^{40} \mathrm{Ar} /{ }^{39} \mathrm{Ar}$ and paleomagnetic results from the Valles rhyolite near Jaramillo Creek, Jemez Mountains, New Mexico, Earth Planet. Sci. Lett., 197, 51-64, 2002.

Smith, J. V., Ductile-brittle transition structures in the basal shear zone of a rhyolite lava flow, eastern Australia, J. Volcanol. Geotherm. Res., 72, 217-223, 1996.

Tan, X., S. Gilder, K. P. Kodama, W. Jiang, Y. Han, H. Zhang, H. Xu, and D. Zhou, New paleomagnetic results from the Lhasa block: Revised estimation of latitudinal shortening across Tibet and implications for dating the India-Asia collision, Earth Planet. Sci. Lett., 293, 396-404, 2010.

Zijderveld, J. D. A., A.C. demagnetization of rocks: Analysis and results, in Methods in Paleomagnetism, edited by D. W. Collinson, K. M. Creer, and S. K. Runcorn, pp. 254-286, Elsevier, Amsterdam, 1967.

K. Uno (e-mail: unokoji@okayama-u.ac.jp), Y. Kaneshige, K. Furukawa, T. Shinmura, and M. Miyoshi 